\title{
Critical Role of the Astrocyte for Functional Remodeling in Contralateral Hemisphere of Somatosensory Cortex after Stroke
}

\author{
Yusuke Takatsuru, ${ }^{1}$ Kei Eto, ${ }^{3,4}$ Ryosuke Kaneko, ${ }^{2}$ Hiroko Masuda, ${ }^{1}$ Noriaki Shimokawa, ${ }^{1}$ Noriyuki Koibuchi, ${ }^{1 *}$ \\ and Junichi Nabekura ${ }^{3,4,5 *}$ \\ ${ }^{1}$ Department of Integrative Physiology, and ${ }^{2}$ Institute of Experimental Animal Research, Gunma University Graduate School of Medicine, Maebashi, \\ Gunma 371-8511, Japan, ${ }^{3}$ Division of Homeostatic Development, National Institute for Physiological Sciences, Okazaki, Aichi 444-8585, Japan, ${ }^{4}$ CREST, \\ Japan Science and Technology Agency, Kawaguchi, 332-0012, Japan, and ${ }^{5}$ Graduate University for Advanced Studies, Hayama, Kanagawa 240-0193, Japan
}

After ischemic stroke, the corresponding area contralateral to the lesion may partly compensate for the loss of function. We previously reported the remodeling of neuronal circuits in the contralateral somatosensory cortex (SSC) during the first week after infarction for processing bilateral information, resulting in functional compensation. However, the underlying processes in the contralateral hemisphere after stroke have not yet been fully elucidated. Recent studies have shown that astrocytes may play critical roles in synaptic reorganization and functional compensation after a stroke. Thus, we aim to clarify the contribution of astrocytes using a rodent stroke model. In vivo calcium imaging showed a significantly large number of astrocytes in the contralateral SSC responding to ipsilateral limb stimulation at the first week after infarction. Simultaneously, extracellular glutamine level increased, indicating the involvement of astrocytes in the conversion of glutamate to glutamine, which may be an important process for functional recovery. This hypothesis was supported further by the observation that application of (2S,3S)-3-\{3-[4-(trifluoromethyl)benzoylamino]benzyloxy\} aspartate, a glial glutamate transporter blocker, disturbed the functional recovery. These findings indicate the involvement of astrocytes in functional remodeling/recovery in the area contralateral to the lesion. Our study has provided new insights into the mechanisms underlying synaptic remodeling after cerebral infarction, which contributes to the development of effective therapeutic approaches for patients after a stroke.

\section{Introduction}

Ischemic stroke is a major cause of mortality and disability in the elderly. Recent advances in functional imaging of the human brain have revealed that the cortical hemisphere contralateral to the infarction plays an important role in functional recovery (Calautti and Baron, 2003; Crosson et al., 2007; Ward, 2007). For example, after infarction of the somatosensory cortex (SSC), postischemic reorganization of the contralateral (intact) SSC at least in part compensates for impaired functions (Chollet et al., 1991; Cao et al., 1998). In animal models, experimental infarction in the unilateral SSC or motor cortex results in functional and

\footnotetext{
Received June 3, 2012; revised Dec. 18, 2012; accepted Jan. 14, 2013.

Author contributions: Y.T. designed research; Y.T., K.E., R.K., H.M., and N.S. performed research; Y.T., K.E., R.K., N.K., and J.N. contributed unpublished reagents/analytic tools; Y.T. analyzed data; Y.T., N.K., and J.N. wrote the paper.

This work was supported by a Core Research for Evolutional Science and Technology from Japan Science and Technology Agency and Grant-in-Aid for Scientific Research (B) (19390055) and (A) (22240042) from the Japan Society for the Scientific of Sciences (JSPS) to J.N., Grant-in-Aid for Scientific Research (B) (19790184 and 21790233) from JSPS to Y.T., Grant-in-Aid for Scientific Research (B) (22700326) from JSPS to R.K., and Life Science Foundation of Japan to R.K.

*N.K. and J.N. contributed equally to this work.

The authors declare no competing financial interests.

Correspondence should be addressed to Dr. Yusuke Takatsuru, Department of Integrative Physiology, Gunma University Graduate School of Medicine, Maebashi, Gunma 371-8511, Japan. E-mail: takatsur@med. gunma-u.ac.jp.

DOI:10.1523/JNEUROSCI.2657-12.2013

Copyright $\odot 2013$ the authors $\quad 0270-6474 / 13 / 334683-10 \$ 15.00 / 0$
}

structural changes in the remaining intact brain region. Infarction in the SSC changes the receptive field in the contralateral SSC 1 week after a stroke (Reinecke et al., 2003). However, further understanding of the mechanism underlying this compensation in the intact hemisphere is absolutely necessary (Calautti and Baron, 2003).

We previously reported the transient increase in both ipsilateral and contralateral somatosensory stimulus-evoked neuronal activities in the intact hemisphere within $2 \mathrm{~d}$ after the stroke, followed by the increase in turnover rate of mushroom-type synaptic spines, which is usually stable, 1 week after the stroke, was observed by two-photon laser microscopy (TPLM) imaging in vivo (Takatsuru et al., 2009). Four weeks after the stroke, when functional recovery occurred, a new neuronal circuit that responds to ipsilateral somatosensory stimuli is established in the intact hemisphere. Thus, by remodeling neuronal circuits, the intact SSC can process new sensory information to compensate for the loss of SSC function (Takatsuru et al., 2009). However, further study may be required to clarify the mechanisms underlying such anatomical remodeling.

Recent studies have shown the critical roles of astrocyte in functional remodeling in adult brain (Rossi et al., 2007; Zhao and Rempe, 2010). Under physiological conditions, astrocytes are involved in the generation and maturation of neuronal circuits, even in the adult cortex (Theodosis et al., 2008; Pfrieger, 2010). They express glia-specific glutamate transporters (glutamate transporter 
1 [GLT-1]; glutamate-aspartate transporter [GLAST]), which are critical for neuronal transmission (Takayasu et al., 2009). Recent studies indicate that astrocytes also play important roles in angiogenesis, neuronal plasticity, and functional recovery weeks after stroke (Ellison et al., 1999; Carmichael, 2010; Zhao and Rempe, 2010). Thus, we aim to reveal the contribution of astrocytes to functional remodeling in the region contralateral to the site of stroke.

Here, we demonstrate an increase in amplitude of calcium transients in astrocytes in the contralateral SSC during the first week after a stroke, particularly by ipsilateral limb stimulation using in vivo TPLM. In vivo microdialysis technique revealed further a transient increase in extracellular glutamine (Gln) level during the same period without alteration of glutamate (Glu) levels. Furthermore, blockade of the Glu transporter using (2S,3S)-3-\{3-[4-(trifluoromethyl)benzoylamino]benzyloxy\} aspartate (TFB-TBOA), a glia-specific Glu transporter antagonist (Shimamoto et al., 2004; Tsukada et al., 2005), disturbed the functional recovery. These findings indicate the activation of astrocytes to take up extracellular Glu and convert it into Gln (Norenberg and Martinez-Hernandez, 1979; Sibson et al., 2001; Hertz and Zielke, 2004).

\section{Materials and Methods}

This study was approved by the Animal Care and Experimentation Committee, Gunma University, and the National Institutes of Natural Sciences. All efforts were made to minimize the suffering and number of animals used in this study.

\section{Animals}

Adult male C57BL/6J mice (2.5-5 months of age; purchased from SLC Japan) were used in this study. All mice were housed with food and water ad libitum under controlled temperature $\left(25 \pm 5^{\circ} \mathrm{C}\right)$, humidity, and illumination (12:12 light-dark cycle; lights on at 6:00 A.M.). Cages were changed once a week. All experiments were performed on mice in the first week (1 week group; 5-7 d after stroke) and second week (2 week group; 8-12 d after stroke) after the stroke, and 2-7 d after sham surgery, except in the von Frey test, in which experiments were performed 2-3 d before and 2, 7, 14, and $28 \mathrm{~d}$ after the stroke/sham surgery.

\section{Photothrombosis}

As previously reported, Rose Bengal solution was used to induce thrombotic infarction (Takatsuru et al., 2009). To facilitate photoactivation in the right SSC ( $1-3 \mathrm{~mm}$ lateral; -1.5 to $1 \mathrm{~mm}$ anterior of bregma), a $2 \times$ $2 \mathrm{~mm}$ region of the skull was thinned to $50 \%$ of original thickness using a high-speed drill (FST) under anesthesia induced with ketamine/xylazine $(22.5 \mathrm{mg} / \mathrm{ml}$ ketamine and $1 \mathrm{mg} / \mathrm{ml}$ xylazine in $0.9 \% \mathrm{NaCl}$, i.p.; 5 $\mathrm{ml} / \mathrm{kg}$ ). After skull thinning, an intravenous injection of $2 \%$ (w/v in $0.9 \%$ $\mathrm{NaCl}$ ) Rose Bengal solution ( $16 \mathrm{mg} / \mathrm{kg}$ ) was performed. To initiate focal photoactivation, the thinned region of the skull was illuminated with a green mercury lamp [530-550 nm, $17 \mathrm{~mW}$; focused with $4 \times$ objective lens, numerical aperture (NA) 0.13] for $15 \mathrm{~min}$. A large stroke covering the entire SSC can be generated by this procedure (Takatsuru et al., 2009). When the size of the stroke was smaller than expected, data were not included in the analysis. Sham-operated mice (Sham group) were treated similarly with the omission of either the laser illumination or the Rose Bengal injection (only $0.9 \% \mathrm{NaCl}$ was injected). We did not observe any damage or structural changes in dendrites related to the sham surgery. After the surgery, mice were housed individually in a cage $(19 \times$ $26 \times 13 \mathrm{~cm})$ and allowed to recover.

\section{In vivo calcium imaging}

Multicell bolus loading of membrane-permeable calcium indicator Oregon Green 488 BAPTA-1 (OGB-1) AM (Invitrogen) and sulforhodamine 101 (SR101; Sigma-Aldrich) in layers $2 / 3$ neuron and astrocytes (100$200 \mu \mathrm{m}$ below the cortical surface; $156.5 \pm 4.5 \mu \mathrm{m}, n=37$; two or three imaging field per mouse). Size of imaging field $(157 \times 157 \mu \mathrm{m})$ was performed as previously described (Kerr et al., 2005; Eto et al., 2011). Mice were anesthetized with urethane $(1.7 \mathrm{~g} / \mathrm{kg}$ body weight, i.p.) and atropine $(0.4 \mathrm{mg} / \mathrm{kg}$ body weight, i.p.). After the application, OGB- 1 with SR101 was excited at $800 \mathrm{~nm}$. A water-immersion objective $(20 \times$, NA $0.95 ; 40 \times$, NA 0.8 ; all from Olympus) was used to acquire images. Images $(128 \times 128$ pixels, $0.188 \mathrm{~s}$ per frame) were analyzed using Olympus Fluoview software. Four-limb vibrotactile stimuli $(1 \mathrm{~s}, 140 \mathrm{~Hz})$ (Takatsuru et al., 2009) were repeatedly applied at each imaging. The baseline intensity $\mathrm{F}_{0}$ was obtained by averaging the fluorescent intensities during the prestimulus period ( 15 frames; $2.82 \mathrm{~s}$ ). Cells were considered responsive when the change in fluorescence intensity was $>10 \%$ of the baseline value $>3$ times per 10 stimuli in each limb, which was defined as the "threshold" in the present study. The relative amplitude of calcium transients was calculated as $\Delta \mathrm{F} / \mathrm{F}_{0}\left(\Delta \mathrm{F}=\mathrm{F}-\mathrm{F}_{0}\right)$. The peak amplitude of the response showing in Figures 2 and 3 was considered as average from $>3$ responses. Calcium transients of the astrocytes in the present study may be more rapid than those in previous studies (Winship et al., 2007; Winship and Murphy, 2008). However, the ratio of calcium transients in astrocytes to that in neuropils is not markedly different from those in previous studies (Winship et al., 2007). Thus, an increase in calcium transients of SRS101-positive astrocytes (Winship et al., 2007; Winship and Murphy, 2008; Eto et al., 2011), induced by somatosensory stimulation in hemisphere contralateral to infarction, is similar to those in the peri-infarcted area. The average response from neuropil around astrocytes was negligible (see Fig. 1). Thus, contamination of such response did not affect the result of analysis of response from neuron/astrocyte.

\section{Real-time RT-PCR analysis of GLT-1, GLAST, and Gln} synthetase $m R N A s$

The expression levels of GLT-1, GLAST, and Gln synthetase (GS) mRNAs in the contralateral SSC were measured by real-time RT-PCR technique (Kaneko et al., 2009) using tissue samples obtained from mice in 1 week, 2 week, and Sham groups. After extraction of RNA followed by cDNA synthesis, PCR was performed with the SYBR Premix ExTaq II (Takara) using a LightCycler 480 (Roche). Each value was normalized with the expression level of $\beta_{2}$-microglobulin $\left(\beta_{2}-\mathrm{m}\right)$ mRNA and expressed as a level relative to that in the Sham group (100\%). The primers used for amplifying each cDNA fragment (127 bp in GLT-1, $159 \mathrm{bp}$ in GLAST, $144 \mathrm{bp}$ in GS, and $109 \mathrm{bp}$ in $\beta_{2}$-m) were as follows: GLT-1-sense, 5'-GGA AGA TGG GTG AAC AGG C-3'; GLT-1-antisense, 5' -TTC CCA CAA ATC AAG CAG G-3'; GLAST-sense, 5' -ACG GTC ACT GCT GTC ATT G-3' (Brito et al., 2009); and GLAST antisense, 5' -TGT GAC GAG ACT GGA GAT GA-3' (Brito et al., 2009); GS sense, 5' -TTC CGC AAA GAC CCC AAC-3'; and GS antisense, 5' -TTC CTG CTC CAT TCC AAA CC- $3^{\prime}$; and $\beta_{2}$-m sense, $5^{\prime}$-CCC TGG TCT TTC TGG TGC TT- $3^{\prime}$; and $\beta_{2}-\mathrm{m}$ antisense, $5^{\prime}$-ATG TTC GGC TTC CCA TTC TC-3' (Kaneko et al., 2009).

\section{Western blot}

GLT-1 protein levels in the cerebrum were measured by Western blotting. Protein extraction from the brain tissues was performed as described previously (Shimokawa et al., 2010). Briefly, a part of the cerebrum was homogenized in lysis buffer-containing protease inhibitors and separated by SDS-PAGE. Immunoblotting was performed with anti-GLT-1 antibody (EAAT2 antibody, 1:1000, Cell Signaling Technology) and with anti-rabbit IgG coupled to HRP (GE Healthcare). The antibody-antigen complexes were detected using the ECL system (GE Healthcare). Blots were reprobed with an anti- $\beta$-actin antibody (Cell Signaling Technology) for monitoring the quantity of protein.

\section{Behavioral tests}

Spontaneous locomotor activity in general cage. To determine the optimal time points for in vivo microdialysis, $24 \mathrm{~h}$ spontaneous general-cage locomotor activity was recorded using infrared motion sensors (NS-ASS01; Ohara). The number of infrared-beam crossings per hour was continuously recorded and summarized. The recording was started at 18:00 for the Sham group ( $7 \mathrm{~d}$ after the sham surgery), or 2,7 , and $14 \mathrm{~d}$ after the stroke.

von Frey hair test. Mice were individually placed on an elevated metalwire mesh table (Takatsuru et al., 2009). A von Frey filament was applied 
to the middle plantar surface of a hindpaw until the filament was bent. The filament was held in this position for $1 \mathrm{~s}$. Only robust and immediate withdrawal responses to the stimulus were counted as withdrawal responses. Each trial consisted of the filament being applied eight times at $30 \mathrm{~s}$ intervals. The mechanical nociceptive threshold was considered as the lowest force that evoked a paw withdrawal in at least $50 \%$ of trials. The value of the von Frey test was expressed as a ratio of the value of nociceptive threshold "after inducing the stroke" divided by "before inducing the stroke" (see Fig. 7).

\section{In vivo microdialysis}

A guide cannula was inserted into the SSC through the cranial window ( $\phi$ $0.5 \mathrm{~mm}$ ) located $1.5-2 \mathrm{~mm}$ lateral to the sagittal suture and -1.5 to $1 \mathrm{~mm}$ anterior to the bregma under ketamine/xylazine anesthesia. Mice were allowed to recover from the surgery for at least $2-3 \mathrm{~d}$ before the experiments. Each experiment was conducted in the dark phase (18:00-6:00) in their home cages. A microdialysis probe $(0.37 \mathrm{~mm}$ in diameter and 1.5 $\mathrm{mm}$ in membrane length) was inserted into the guide cannula at $4-6 \mathrm{~h}$ before the dialysis. The probe was perfused at the rate of $1 \mu \mathrm{l} / \mathrm{min}$ with HEPES buffer (in mM: $\mathrm{NaCl}, 140.0 ; \mathrm{KCl}, 2.5 ; \mathrm{CaCl}_{2}, 2.0 ; \mathrm{MgCl}_{2}, 1.0$; HEPES, 5.0; glucose, 10.0; $\mathrm{pH} 7.4$ ). After a $4-6 \mathrm{~h}$ stabilization period, three samples were collected (90 min per sample; from 18:00-22:30, three samples per mouse). Then, Glu, Gln, and D-serine were immediately measured by high-performance liquid chromatography (EICOM) (Parent et al., 2001). The concentrations of Glu and Gln were normalized using a calibration curve from $100 \mu \mathrm{M}$ to $10 \mathrm{nM}$, and three values per mouse were averaged before statistical analysis. After termination of the dialysis, the mice were killed under ketamine/xylazine anesthesia, and stroke size was examined. The size of stroke in each mouse was sufficiently large to cover the entire area of the right SSC (data not shown), and the size was similar to those in a previous report (Takatsuru et al., 2009).

\section{Application of TFB-TBOA}

TFB-TBOA, a selective antagonist of glial Glu transporters (GLT-1 and GLAST) (Shimamoto et al., 2004; Tsukada et al., 2005), was applied through a microdialysis probe. A stock solution of TFB-TBOA in DMSO $(10 \mathrm{~mm})$ was diluted with HEPES buffer to 200 or $20 \mathrm{~nm}$ and applied by in vivo microdialysis $(1 \mu \mathrm{l} / \mathrm{min})$ in the dark phase 3 and $4 \mathrm{~d}$ after the sham surgery and stroke induction. To confirm the distance of diffused drug from the probe, methylene blue (1.0\%) was applied through the probe. By using this method, methylene blue was diffused $0.51 \pm 0.04 \mathrm{~mm}$ in diameter around the probe $(n=9$; see Fig. $7 A)$. For control, $0.002 \%$ $\mathrm{DMSO} / \mathrm{HEPES}$ buffer was also applied. The perfusion rate was $1 \mu \mathrm{l} / \mathrm{min}$ in the microdialysis study.

\section{Statistical analysis}

All the data were compared by one- or two-way ANOVA. Post hoc comparison was performed by the Bonferroni test using Excel statistics (Esumi). The difference was considered significant at $p<0.05$. All values are presented as mean \pm SEM.

\section{Results}

\section{Changes in neuronal responses to vibrotactile stimulation after contralateral SSC infarction}

To examine whether the responses to limb stimulation are altered after the stroke, in vivo calcium imaging was performed. Figure $1 B$ (left panels) shows representative TPLM images in layer $2 / 3$ of the SSC. Neurons and astrocytes were stained by the green fluorescent dye (OGB-1). Astrocytes were identified by the staining of their marker, SR101, by the red fluorescent dye. Merging of green and red fluorescences shows astrocytes with the yellow color, allowing their differentiation from neurons (green). The changes in intracellular calcium level in each numbered cell are also shown (Fig. $1 B$, right panels). Some cells responded only to single-limb stimulus, whereas other cells responded to multiplelimb stimulation. The decay time for calcium signal $(\tau)$ was $0.42 \pm 0.02 \mathrm{~s}$ in neurons, $0.45 \pm 0.02 \mathrm{~s}$ in astrocytes, and $0.23 \pm$
$0.02 \mathrm{~s}$ in neuropils. Response from neuropils was rather small, and the average response was negligible (Fig. $1 B$ ). Thus, contamination of response from neuropils did not affect the analysis of response from neurons/astrocytes. As shown in Figure 2A, 20\% of neurons responded either to right forelimb $(\mathrm{cFL})$ or right hindlimb (cHL) stimulation in the Sham group (Table $1 ; n=5$ mice), whereas $\sim 30 \%$ of neurons responded after the stroke (Table $1 ; n=5$ mice both in 1 week and 2 weeks). Statistically, the stroke did not significantly alter the number of neurons responding to contralateral limb stimulation (one-way ANOVA: cFL; $\left.F_{(2,12)}=3.33 ; p=0.071 ; \mathrm{cHL} ; F_{(2,14)}=2.21 ; p=0.152\right)$. In contrast, although the number of neurons responding to either left forelimb (iFL) or left hindlimb (iHL) stimulation was small in the Sham group, the number of such neurons significantly increased after the stroke (one-way ANOVA: iFL, $F_{(2,12)}=18.62$, $p=0.0002$; iHL, $\left.F_{(2,12)}=20.66, p=0.0001\right)$. The numbers of neurons responding to either iFL or iHL stimulation in the 1 week group and the 2 week group were significantly larger than those in the Sham group (Bonferroni test: iFL, $t_{(9)}=3.68, p=0.003$ vs 1 week; $t_{(9)}=6.06, p=0.00006$ vs 2 week. iHL; $t_{(9)}=4.18, p=$ 0.001 vs 1 week, $t_{(9)}=6.32, p=0.00004$ vs 2 week). As shown in Figure $2 B$, most of the neurons in the Sham group responded only to single-limb stimulation $(82.3 \pm 2.3 \%$, mainly contralateral limb) and a small number of neurons responded to multiplelimb stimulation (neurons responding to two-limb stimulation, $15.9 \pm 2.5 \%$; three- or four-limb stimulation, $1.8 \pm 1.1 \%)$. On the other hand, in the stroke-induced mice (Stroke group), the responses to the stimulation were significantly altered (two-way ANOVA: group $\times$ number of responses, $F_{(7,39)}=7.60 ; p=$ $0.00004)$. A smaller number of neurons responded only to singlelimb stimulation both in the 1 week group $(50.0 \pm 9.6 \%)$ and the 2 week group $(39.8 \pm 5.7 \%)$ compared with those in the Sham group (Bonferroni test: 1 week, $t_{(9)}=3.46, p=0.005 ; 2$ week, $\left.t_{(9)}=4.55, p=0.00007\right)$. In contrast, a larger number of neurons responded to two-limb stimulation in both the 1 week group $(33.6 \pm 5.5 \%)$ and the 2 week group $(39.8 \pm 5.7 \%)$ compared with those in the Sham group (Bonferroni test: 1 week, $t_{(9)}=$ $3.34, p=0.006 ; 2$ week, $\left.t_{(9)}=3.92, p=0.002\right)$. The number of neurons responding to three- or four-limb stimulation was $17.3 \pm 5.4 \%$ in the 1 week group, which was not statistically different from that in the Sham group (Bonferroni test: $t_{(9)}=$ $2.54, p=0.026)$, whereas it significantly increased in the 2 week group $\left(39.8 \pm 5.7 \%, t_{(9)}=3.61, p=0.004\right)$. Among the neurons that responded to two-limb stimulation in the Sham group, most of them responded to cFL and $\mathrm{cHL}$ and a small number of neurons $(6.7 \pm 6.7 \%)$ responded to stimulation of both sides (i.e., $\mathrm{cFL}$ and $\mathrm{iFL}$ ) (Fig. 2B, inset). In the stroke group, however, the number of neurons that responded to stimulation of both sides significantly increased (one-way ANOVA: $F_{(2,12)}=6.82, p=$ 0.01 ). In the 1 week group, $44.9 \pm 12.3 \%$ of neurons responded to two-limb stimulation of both sides (Fig. $2 B$, inset). In the 2 week group, a significantly larger number of neurons than that in the Sham group responded to two-limb stimulation of both sides $\left(56.7 \pm 10.2 \%, t_{(9)}=3.54, p=0.004\right)$. These findings are consistent with our previous electrophysiological study showing the reorganization of neural circuits to process bilateral somatosensory information in the hemisphere contrarateral to the infarction (Takatsuru et al., 2009).

As shown in Figure 2C, the peak amplitude of response in the Sham group was $\sim 13 \% \Delta \mathrm{F} / \mathrm{F}_{0}$. In the stroke animals, these values were not markedly different from those in the Sham group, although a weak but significant difference was observed in cHL stimulation (one-way ANOVA: $\mathrm{cHL}, F_{(2,236)}=5.07, p=0.007$ ). 
A
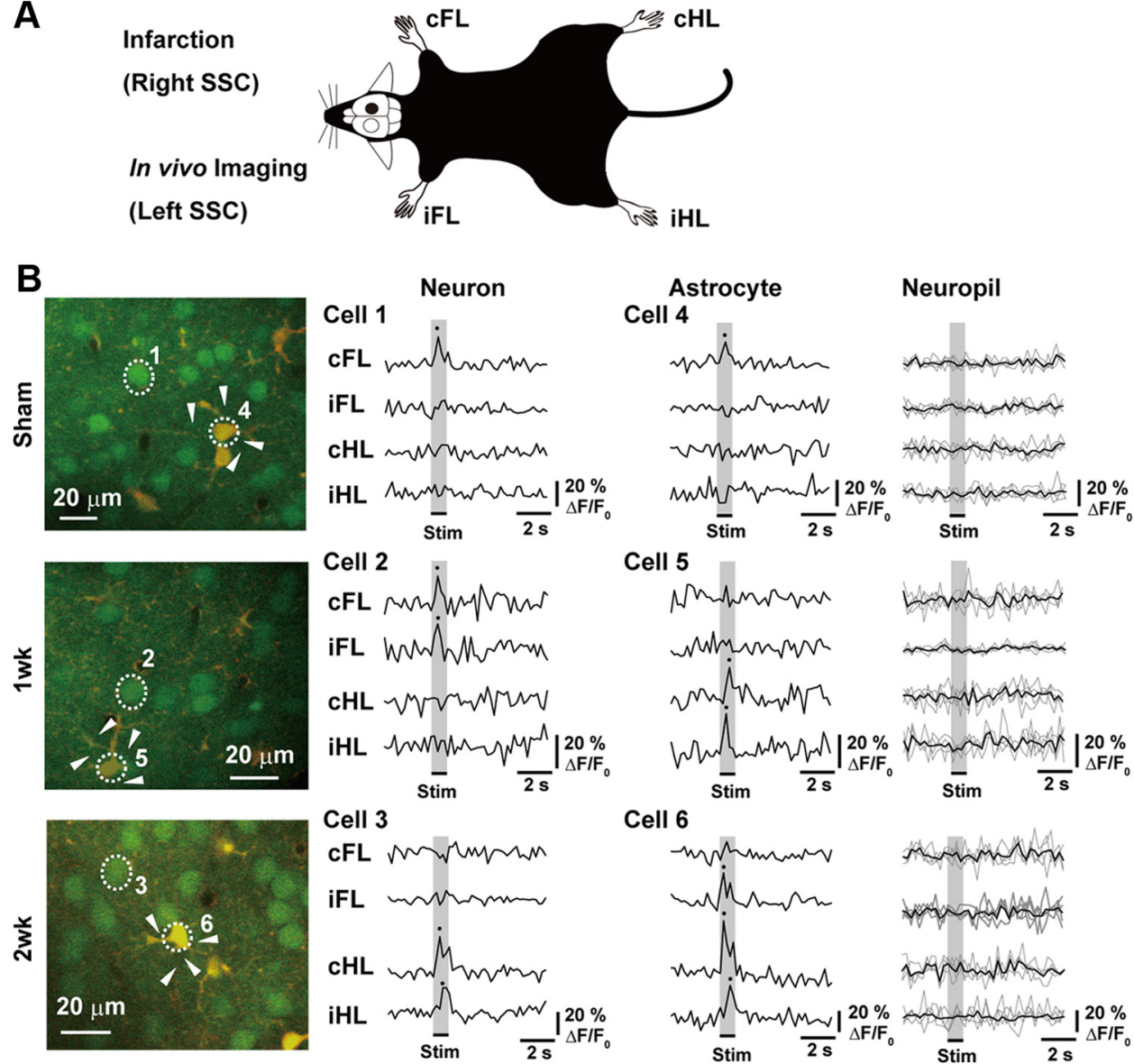
Cell 5
Mrownum
whymon

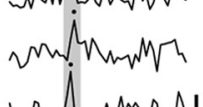

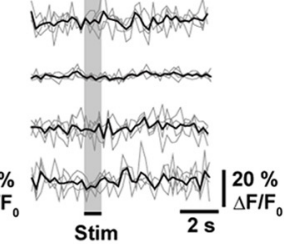

Cell 6

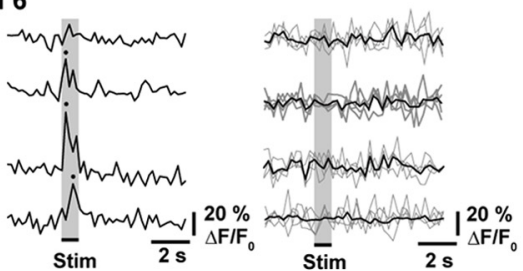

Figure 1. Effect of unilateral SSC stroke on limb-stimulation-induced intracellular calcium concentration changes in neurons and astrocytes in contralateral SSC. A, Schematic drawing of experimental design. All strokes were made in right SSC, and images or samples were taken from left SSC. B, Representative TPLM images (left panels) and traces of changes in intracellular calcium level in numbered cells (right panels) in the mice of sham-operated (Sham), first week (5-7 d after stroke), and second week (8-12 d after stroke) after the stroke (1 week and 2 week groups, respectively). Each trace indicates the $\Delta \mathrm{F} / \mathrm{F}_{0} \%$ of calcium transients induced by limb stimulation. In the case of neuropils, responses from different neuropils (arrowheads) were shown in thin lines. Their average was shown in the thick line. The average of response from neuropils was not above the threshold for signal analysis.

In the 1 week group, the peak amplitude of response to cHL stimulation was $13.5 \pm 0.3 \% \Delta \mathrm{F} / \mathrm{F}_{0}$, which was not significantly different from that in the Sham group, whereas in the 2 week group, the peak amplitude was $14.6 \pm 0.4 \% \Delta \mathrm{F} / \mathrm{F}_{0}$, which was significantly different from that in the Sham group $\left(t_{(116)}=3.03\right.$, $p=0.007)$.

These findings indicate that the number of neurons receiving multiple inputs, particularly from ipsilateral limbs, was increased by the stroke, but the peak amplitude was not markedly altered.

\section{Changes in astrocyte response to vibrotactile stimulation after contralateral SSC infarction}

In previous studies, the number of reactive astrocytes was not increased in the contralateral area of infarction (Zhang et al., 1999; Olson and McKeon, 2004). In this study, the average number of astrocytes in an imaging field was $10.5 \pm 1.0$ in Sham, $12.3 \pm 1.8$ in 1 week, and $9.2 \pm 1.0$ in 2 week. These values were not statistically different (one-way ANOVA: $F_{(2,34)}=0.46 ; p=$ 0.638). However, the number of astrocytes responding to limb stimulation was altered by the stroke. As shown in Figure 3A, the number of astrocytes showing a significant response to limb stimulation was small in the Sham group (Table 2). In the Stroke group, however, the number of astrocytes responding to limb stimulation significantly increased (two-way ANOVA: group $\times$ number of responses, $\left.F_{(7,39)}=3.93 ; p=0.004\right)$. In the 1 week group, the numbers of astrocytes responding to each limb stimulation was $\sim 30-40 \%$. Although the amplitude of response tend to increase, values of response to contralateral limb stimulation ( $\mathrm{cFL}$ and $\mathrm{cHL}$ ) were not statistically different between the 1 week group and the Sham group (Bonferroni test: $\mathrm{cFL}, t_{(51)}=2.37, p=$ 0.035 ; cHL, $\left.t_{(63)}=2.19, p=0.049\right)$, whereas those for the ipsilateral limb stimulation (iFL and iHL) were significantly different between the 1 week group and the Sham group $\left(t_{(39)}=3.11, p=\right.$ 0.009 ; $\left.\mathrm{cHL}, t_{(50)}=3.02, p=0.011\right)$. In the 2 week group, the number of astrocytes responding to each limb stimulation was $\sim 40-75 \%$, which are all significantly different from those in the Sham group $\left(\mathrm{cFL}, t_{(9)}=3.92, p=0.002 ; \mathrm{iFL}, t_{(9)}=7.57, p=\right.$ $0.00001 ; \mathrm{cHL}, t_{(9)}=5.12, p=0.0003$; iHL, $t_{(9)}=5.06, p=$ 0.0003 ).

As shown in Figure $3 B$, a significantly larger number of astrocytes $(83.1 \pm 7.6 \%)$ responded only to the single-limb stimulation in the Sham group. A small number of astrocytes responded to multiple-limb stimulation (cells responding to two-limb stimulation, $14.9 \pm 6.2 \%$; three- or four-limb stimulation, $2.0 \pm$ $2.0 \%)$. Unlike neurons, however, no astrocytes showed preference in response to contralateral and ipsilateral limb stimulation. In the Stroke group, on the other hand, the distribution of the response was significantly changed. Few cells responded only to single-limb stimulation (one-way ANOVA: $F_{(2,12)}=15.88, p=$ 0.0004 ), whereas a larger number of cells responded to two-limb 

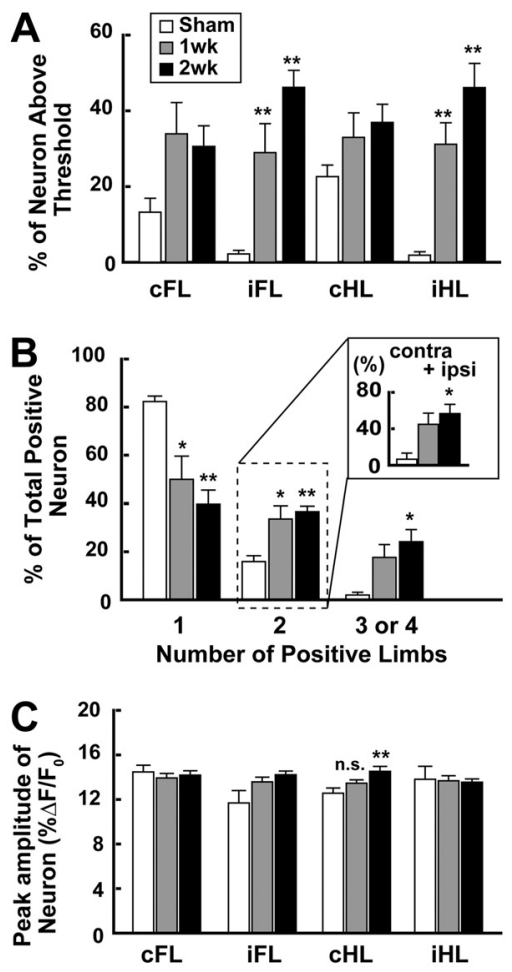

Figure 2. The number of neurons that responded to ipsilateral limb stimulation increased after unilateral SSC stroke in contralateral SSC. A, Percentage of neurons responding to each limb stimulation. The percentage significantly increased after the stroke, particularly in the iFLand $\mathrm{HHL}$-stimulated groups. $\boldsymbol{B}$, Percentage of neurons responding to single-limb or multiplelimb stimulation $(2,3$, or 4). The percentage in each group was calculated by dividing the number of neurons responding to one, two, three, or four limb stimulation by the number of all neurons showing a positive response to any limb stimulation. Inset, The percentage of neurons responding to both ipsilateral and contralateral limb stimulations (cFL + iFL or $\mathrm{CHL}+\mathrm{iHL}$ ). C, Peak amplitude $\left(\% \Delta \mathrm{F} / \mathrm{F}_{0}\right)$ of the change in intracellular calcium transients after limb stimulation. No significant changes were observed, except when CHL was stimulated in the 2 week group, which showed a weak increase. In all the graphs, data are mean \pm SEM. ${ }^{*} p<0.05$, compared with Sham (Bonferroni test). ${ }^{* *} p<0.01$, compared with Sham (Bonferroni test). n.s. indicates not significant.

Table 1. Results of in vivo Ca imaging (neuron)

\begin{tabular}{ccll}
\hline & $\begin{array}{l}\text { Sham } \\
(n=5 \text { mice })\end{array}$ & $\begin{array}{l}1 \text { week } \\
(n=5 \text { mice })\end{array}$ & $\begin{array}{l}2 \text { week } \\
(n=5 \text { mice })\end{array}$ \\
\hline $\begin{array}{l}\text { Response (\%) (number of cells) } \\
\text { CFL }\end{array}$ & $13.2 \pm 3.7$ & $33.9 \pm 8.3$ & $30.6 \pm 5.4$ \\
& $(30 / 204)$ & $(81 / 238)$ & $(96 / 303)$ \\
iFL & $2.2 \pm 0.9$ & $29.0 \pm 7.6^{*}$ & $46.2 \pm 4.5^{*}$ \\
& $(6 / 204)$ & $(74 / 238)$ & $(137 / 303)$ \\
CHL & $22.6 \pm 3.0$ & $33.0 \pm 6.5$ & $36.9 \pm 4.8$ \\
& $(46 / 204)$ & $(90 / 238)$ & $(101 / 303)$ \\
iHL & $1.9 \pm 0.9$ & $31.2 \pm 5.7^{*}$ & $46.1 \pm 6.4^{*}$ \\
& $(5 / 204)$ & $(83 / 238)$ & $(131 / 303)$ \\
Amplitude $\left(\% \Delta \mathrm{F} / \mathrm{F}_{0}\right)$ & & & \\
CFL & $14.5 \pm 0.6$ & $14.0 \pm 0.4$ & $14.2 \pm 0.4$ \\
iFL & $10.7 \pm 1.1$ & $13.6 \pm 0.4$ & $14.2 \pm 0.3$ \\
CHL & $12.6 \pm 0.5$ & $13.5 \pm 0.3$ & $14.6 \pm 0.4^{*}$ \\
iHL & $13.8 \pm 1.2$ & $13.7 \pm 0.5$ & $13.6 \pm 0.3$ \\
\hline
\end{tabular}

${ }^{*} p<0.01$, compared with Sham (Bonferroni test).

$\left(F_{(2,12)}=3.01, p=0.087\right)$, or three- or four-limb stimulation $\left(F_{(2,12)}=9.77, p=0.003\right)$. In the 1 week group, $38.1 \pm 10.1 \%$ of astrocytes responded only to single-limb stimulation, which was significantly lower than that in the Sham group (Bonferroni test: $\left.t_{(9)}=3.82, p=0.002\right)$. In contrast, the number of cells respond-
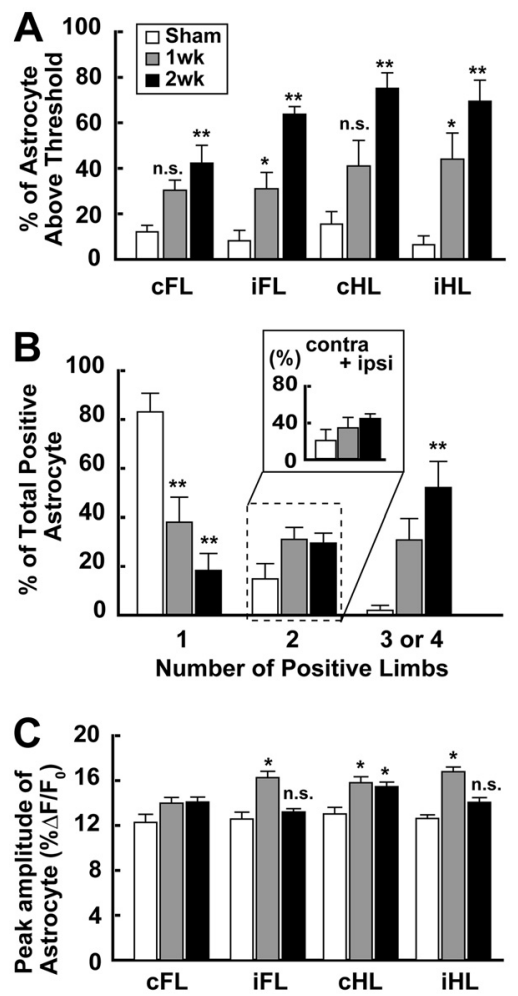

Figure 3. The amplitude of calcium transients of astrocytes that responded to ipsilateral limb stimulation increased after the unilateral SSC Stroke in the contralateral SSC. A, Percentage of astrocytes responding to each limb stimulation. The percentage particularly increased in the iFL- and iHL-stimulated groups after the stroke. $\boldsymbol{B}$, Percentage of astrocytes responding to single-, or multiple-limb stimulation ( 2,3 , or 4$)$. The percentage in each group was calculated by dividing the number of astrocytes responding to one-, two-, three-, or four-limb stimulation by the number of all astrocytes showing a positive response to any limb stimulation. Inset, The percentage of astrocytes responding to both ipsilateral and contralateral limb stimulations (CFL + iFL or $\mathrm{CHL}+\mathrm{iHL}$ ). The number of astrocytes receiving information on only single-limb stimulation markedly decreased after the stroke. $C$, Peak amplitude $\left(\% \Delta F / F_{0}\right)$ of the change in intracellular calcium transients after limb stimulation. No significant changes were observed, except when $\mathrm{CHL}$ was stimulated in the 2 week group, which showed a weak increase. Interestingly, the amplitude significantly increased particularly in the iFL- and iHL-stimulated in the 1 week group. ${ }^{*} p<0.05$, compared with Sham (Bonferroni test). ${ }^{* *} p<0.01$, compared with Sham (Bonferroni test). n.s. indicates not significant.

Table 2. Results of in vivo Ca imaging (astrocytes)

\begin{tabular}{ccll}
\hline & $\begin{array}{l}\text { Sham } \\
(n=5 \text { mice })\end{array}$ & $\begin{array}{l}1 \text { week } \\
(n=5 \text { mice })\end{array}$ & $\begin{array}{l}2 \text { week } \\
(n=5 \text { mice })\end{array}$ \\
\hline $\begin{array}{l}\text { Response (\%) (number of cells) } \\
\text { CFL }\end{array}$ & $12.1 \pm 2.9$ & $30.4 \pm 4.5$ & $42.3 \pm 7.8^{* *}$ \\
& $(15 / 124)$ & $(37 / 136)$ & $(54 / 128)$ \\
iFL & $8.2 \pm 4.6$ & $31.1 \pm 7.0^{*}$ & $63.7 \pm 3.4^{* *}$ \\
& $(5 / 124)$ & $(35 / 136)$ & $(72 / 128)$ \\
CHL & $15.5 \pm 5.5 \%$ & $41.0 \pm 11.3$ & $75.1 \pm 6.8^{* *}$ \\
& $(18 / 124)$ & $(46 / 136)$ & $(92 / 128)$ \\
iHL & $6.4 \pm 3.9$ & $44.0 \pm 11.4^{*}$ & $69.4 \pm 9.3^{* *}$ \\
& $(4 / 124)$ & $(47 / 136)$ & $(76 / 128)$ \\
Amplitude $\left(\% \Delta \mathrm{F} / \mathrm{F}_{0}\right)$ & & & \\
CFL & $12.3 \pm 0.7$ & $14.0 \pm 0.5$ & $14.1 \pm 0.4$ \\
iFL & $12.6 \pm 0.6$ & $16.3 \pm 0.6^{*}$ & $13.2 \pm 0.3$ \\
CHL & $13.0 \pm 0.6$ & $15.8 \pm 0.5^{*}$ & $15.5 \pm 0.4^{*}$ \\
iHL & $12.6 \pm 0.3$ & $16.8 \pm 0.4^{*}$ & $14.1 \pm 0.4$ \\
\hline
\end{tabular}

${ }^{*} p<0.05$, compared with Sham (Bonferroni test). ${ }^{*} p<0.01$, compared with Sham (Bonferroni test). 


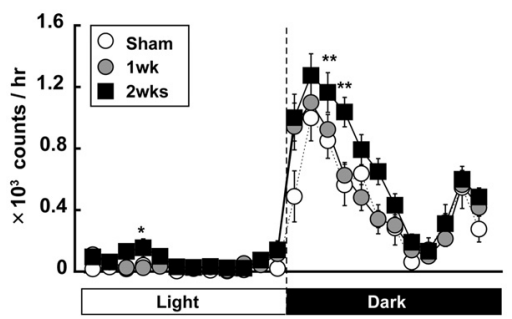

Figure 4. Locomotor activity in the general cage significantly increased after the stroke in the contralateral SSC. Circadian changes in spontaneous locomotor activity in general cage. Locomotor activity was measured using infrared motion sensors. The number of infrared-beam crossings per hour was continuously recorded and summarized. The activity significantly increased from 20:00 to 22:00 in the 2 week group. ${ }^{*} p<0.05$, compared with Sham (Bonferroni test); ${ }^{* *} p<0.01$, compared with Sham (Bonferroni test).

ing to multiple-limb stimulation tended to increase. In the 1 week group, $31.1 \pm 4.9 \%$ and $30.8 \pm 8.7 \%$ of astrocytes responded to two-limb and three- or four-limb stimulation in the 1 week group, respectively, which were not statistically different from that in the Sham group. In the 2 week group, the number of astrocytes responding only to single-limb stimulus (18.3 $\pm 7.0 \%)$ was significantly smaller than that in the Sham group (Bonferroni test: $\left.t_{(9)}=5.50, p=0.0001\right)$. The number of astrocytes responding to two-limb stimulation was $29.5 \pm 4.1 \%$, which was not statistically different from that in the Sham group. On the other hand, the number of neurons responding to three- or four-limb stimulation $(52.1 \pm 10.7 \%)$ significantly increased (Bonferroni test: $\left.F_{(2,12)}=9.77, p=0.003 ; t_{(9)}=4.40, p=0.0009\right)$.

As shown in Figure $3 C$, the peak amplitudes of response $(\Delta \mathrm{F} /$ $\mathrm{F}_{0}$ ) in Sham were $\sim 13 \%$. In the Stroke group, the peak amplitude significantly changed, except for cFL (one-way ANOVA: cFL, $F_{(2,103)}=2.07 ; p=0.131 ; \mathrm{iFL}, F_{(2,109)}=14.55, p<0.000001$; $\mathrm{cHL}, F_{(2,153)}=3.82, p=0.024 ; \mathrm{iHL}, F_{(2,124)}=11.51, p=$ $0.00003)$. In the 1 week group, the peak amplitudes of response were $\sim 14-17 \%$. The values for iFL, cHL, and iHL were significantly greater than those in Sham (Bonferroni test: iFL, $t_{(39)}=$ 2.67, $p=0.008$; cHL, $t_{(63)}=2.72, p=0.008$; iHL, $t_{(50)}=2.46$, $p=0.015)$. In the 2 week group, the peak amplitudes of response were $\sim 13-15 \%$. Interestingly, only the amplitude for $\mathrm{cHL}$ was significantly greater than those in the Sham group $\left(\mathrm{cHL} ; t_{(109)}=\right.$ $2.72, p=0.008)$. The values for $\mathrm{iFL}$ and $\mathrm{iHL}$ were the same values as those in the Sham group (iFL, $t_{(76)}=0.47, p=0.637$; iHL, $\left.t_{(79)}=0.84, p=0.400\right)$. These findings indicate the increased activity of astrocytes in the area contralateral to the site of infarction, particularly at the 1 week group and the 2 week group. It should be noted that the amplitude of response to ipsilateral stimulation showed a greater increase.

\section{Increase in Gln concentration during the first week after the stroke}

Because a large number of neurons and astrocytes responded to limb stimulation in the Stroke group, we examined further the changes in Glu and Gln concentration in the contralateral SSC under free-moving conditions by in vivo microdialysis. Before the in vivo microdialysis study, we measured spontaneous generalcage locomotor activity to determine the optimal time of the day for sampling. As shown in Figure 4, both the Sham and Stroke groups showed the increase in the activity during the dark phase with a typical M-shape pattern. Interestingly, locomotor activity significantly increased 2 weeks after stroke (two-way ANOVA: $\left.F_{(69,2808)}=1.33, p=0.038\right)$ at 20:00-21:00 (Bonferroni test: $\left.t_{(80)}=3.57, p=0.0005\right), 21: 00-22: 00\left(t_{(80)}=3.25, p=0.0015\right)$,
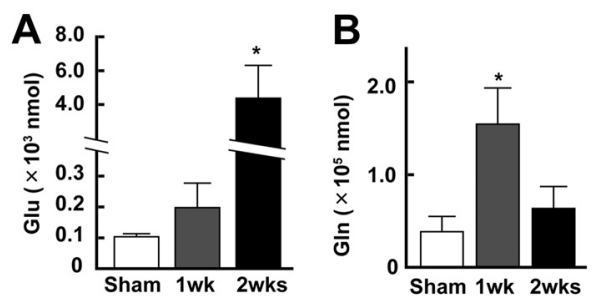

Figure 5. The concentrations of extracellular Glu and GIn significantly changed after the stroke in the contralateral SSC. $A$, Concentration of Glu in the contralateral SSC after the stroke. The concentration significantly increased in the 2 week group. $\boldsymbol{B}$, Concentration of $\mathrm{Gln}$ in the contralateral SSC after the stroke. The concentration was significantly increased in the 1 week group. ${ }^{*} p<0.05$, compared with Sham (Bonferroni test).

and 9:00-10:00 $\left(F_{(3,117)}=4.38, p=0.006 ; t_{(80)}=2.96, p=\right.$ $0.004)$. On the basis of these findings, we decided to perform in vivo microdialysis sampling from 18:00-22:30 because the locomotor activity was greater during this time than at other times of the day, during which somatosensory inputs may increase.

To our surprise, although one-way ANOVA showed the significant effect in the change of Glu concentration after the stroke $\left(F_{(2,27)}=5.51, p=0.0098\right)$, only a slight increase in Glu concentration was observed in the 1 week group (Fig. $5 A)(0.21 \pm 0.08 \times$ $10^{3} \mathrm{nmol}, n=13$ mice) compared with the Sham group $(0.10 \pm$ $0.03 \times 10^{3}$ nmol, $n=8$ mice; Bonferroni test: $t_{(20)}=0.08, p=$ 0.940 ) despite the fact that the number of neurons responding to limb stimulation significantly increased in the 1 week group. On the other hand, the concentration markedly increased in the 2 week group $\left(4.37 \pm 1.94 \times 10^{3} \mathrm{nmol}, n=9\right.$ mice $)$, compared with the Sham group $\left(t_{(21)}=2.76, p=0.01\right)$. As shown in Figure $5 B$, the concentration of Gln significantly increased (determined by one-way ANOVA: $\left.F_{(2,27)}=6.36 ; p=0.0054\right)$, particularly in the 1 week group $\left(1.66 \pm 0.40 \times 10^{5} \mathrm{nmol}\right)$, compared with the Sham group $\left(0.38 \pm 0.17 \times 10^{5} \mathrm{nmol}\right.$; Bonferroni test: $t_{(20)}=$ $2.67, p=0.013)$. Interestingly, the concentration in the 2 week group $\left(0.63 \pm 0.24 \times 10^{5} \mathrm{nmol}\right)$ was not significantly different from that in the Sham group $\left(t_{(21)}=0.48, p=0.632\right)$; however, a larger numbers of neurons and astrocytes in the 2 week group responded to somatosensory stimulation than in the 1 week group. These findings indicate that the metabolism of Glu by astrocytes may be enhanced specifically in 1 week, producing Gln.

We also measured the concentration of D-serine in the Sham and the 1 week groups. No significant difference in its level between them was observed (data not shown).

\section{Uptake of Glu by glial Glu transporter may be important for functional recovery after stroke}

The results of in vivo microdialysis together with TPLM imaging indicate that astrocytes may be activated in the 1 week group, enhancing Glu uptake and conversion to Gln. To test this hypothesis, we examined further the contribution of astrocyteexpressed Glu transporters (GLT-1 and GLAST), which play an important role in the uptake of extracellular Glu (Danbolt, 2001). As shown in Figure 6, the mRNA expression level of GLT-1, a major glial Glu transporter in the cortex (Rothstein, 1996; Danbolt, 2001), significantly increased (one-way ANOVA: $F_{(2,18)}=$ $5.30 ; p=0.017)$ both in the 1 week group $(147.5 \pm 6.8 \%, n=7$. $\left.t_{(13)}=2.82, p=0.012\right)$ and the 2 week group $(150.4 \pm 8.3 \%, n=$ 5. $\left.t_{(11)}=2.73, p=0.014\right)$ compared with the Sham group $(100 \pm$ $17.2 \%, n=7)$. On the other hand, the expression level of GLAST mRNA did not significantly change (the Sham group, $100 \pm$ $12.0 \%$; the 1 week group, $115.8 \pm 3.2 \%$; the 2 week group, 
A
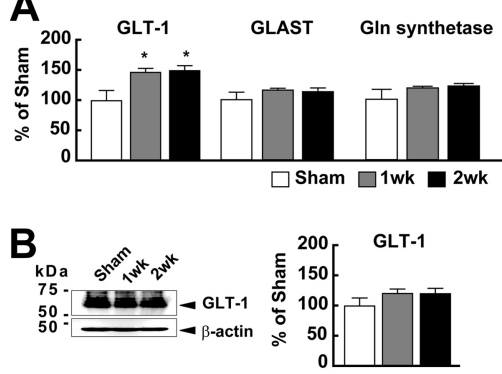

Figure 6. The expression level of GLT-1 mRNA increased after the stroke in the contralateral SSC. A, Expression levels of GLT-1, GLAST, and GS mRNAs. Each value was normalized with the expression level of $\beta_{2}$-m mRNA and expressed as relative levels to that in the Sham group (100\%). The expression of GLT-1 mRNA was significantly increased both at 1 week and 2 weeks. ${ }^{*} p<0.05$, compared with Sham (Bonferroni test). $\boldsymbol{B}$, The protein levels of GLT- 1 were analyzed by Western blotting. Representative immunoblots (left) and quantification (right) of the amount of GLT-1 in the intact SSC are shown. The position of standard molecular masses (kDa) is indicated at the left in immunoblots. There was no statistically different expression level of GLT-1 protein between Sham and Stroke mice.

$112.2 \pm 6.2 \%$; one-way ANOVA: $\left.F_{(2,18)}=1.00, p=0.389\right)$. The expression level of GS, which is expressed in the astrocyte and converts Glu to Gln (Norenberg and Martinez-Hernandez, 1979; Hertz and Zielke, 2004), was also not increased in the stroke mice (Sham group, $100 \pm 16.5 \%$; 1 week group, $118.8 \pm 2.7 \%$; 2 week group, $122.0 \pm 4.1 \%$; one-way ANOVA: $\left.F_{(2,18)}=1.21, p=0.324\right)$.

As shown in Figure $6 B$, the expression level of GLT-1 protein tend to be increased by $20 \%$ (120.7 $\pm 7.4 \%$ in 1 week, $120.5 \pm 9.0 \%$ in 2 week; $n=10$ mice in each time point). However, the change was not statistically significant (one-way ANOVA: $\left.F_{(2,27)}=1.36, p=0.275\right)$ despite the increase in its mRNA expression. These results indicate that the increase in uptake of Glu was potentially achieved by housekeeping Glu transporters after the stroke.

To examine further the involvement of Glu transporters, we applied TFB-TBOA, a selective antagonist of glial Glu transporters (Shimamoto et al., 2004; Tsukada et al., 2005) to inhibit their action. As shown in Figure 7A, injection of 200 nM TFB-TBOA during the dark phase 3 and $4 \mathrm{~d}$ after the stroke significantly changed the concentration of Glu (one-way ANOVA: $F_{(3,24)}=6.26 ; p=0.002$ ). As shown in Figure $7 B$, TFB-TBOA treatment did not significantly increase the concentration of Glu in the Sham group $(0.32 \pm 0.11 \times$ $10^{3} \mathrm{nmol}, n=8$ mice vs DMSO treatment; $0.14 \pm 0.23 \times 10^{3} \mathrm{nmol}$, $n=6$ mice; Bonferroni test: $\left.t_{(13)}=0.051, p=0.960\right)$. On the other hand, this treatment significantly increased the concentration of Glu in the Stroke group $\left(12.08 \pm 4.28 \times 10^{3} \mathrm{nmol}, n=8\right.$ mice vs DMSO treatment; $0.22 \pm 0.08 \times 10^{3} \mathrm{nmol}, n=6$ mice; Bonferroni test: $t_{(13)}$ $=8.86, p=0.003)$. These findings indicate that the concentration of Glu was extremely high $7 \mathrm{~d}$ after the stroke, but astrocytes greatly reduced the concentration of Glu by function of Glu transporters.

Finally, we examined the change in functional recovery by TFB-TBOA treatment after the stroke using the von Frey hair test. In DMSO-treated animals, the somatosensory response to ipsilateral hindlimb stimulation was significantly disturbed $2 \mathrm{~d}$ after the stroke but was recovered on $14 \mathrm{~d}$ after stroke (Fig. 7D). In addition, no functional changes were observed in response to contralateral hindlimb stimulation (Fig. 7C). In TFB-TBOAtreated animals, however, the functional recovery of response to iHL stimulation was markedly delayed until $28 \mathrm{~d}$ after the stroke (Fig. 7E). This change was also detected by application of low-dose (20 nM) of TFB-TBOA (data not shown; Post/ Pre $=1.68 \pm 0.44$ at 2 weeks, $n=6)$. Furthermore, the re- sponse to cHL stimulation, which was not disturbed after the stroke in DMSO-treated animals, was also disturbed by TFBTBOA treatment after the stroke, probably because of the increase in Glu from newly formed synapse from ipsilateral limbs to unaffected somatosensory cortex.

Together, these findings are consistent with the hypothesis that activated astrocytes increased the uptake of Glu by Glu transporters during 1 week, which play an important role in somatosensory compensation.

\section{Discussion}

In the present study, we analyzed the changes in neuronal and astrocyte function in the contralateral SSC after unilateral SSC infarction. After the stroke, neurons started to respond to multiple-limb stimulation, particularly to the stimulation of the ipsilateral limb, without showing changes in the peak amplitude of calcium transients (Fig. 2). On the other hand, the peak amplitude in astrocytes was increased during the first week (Fig. 3). Interestingly, such increases in astrocyte activity were particularly significant in response to ipsilateral limb stimulation. During this period, there was an increase in Gln concentration without alteration in Glu concentration (Fig. 5), which could be the result of the enhancement of the uptake of Glu and conversion to Gln in astrocytes. Such events in astrocytes may be important for functional recovery, as shown by the increase in Glu concentration and disruption of the recovery of response to somatosensory stimulation (Fig. 7) after TFB-TBOA treatment.

\section{Possible involvement of astrocytes in functional remodeling}

One of the important roles of astrocytes is the uptake of Glu released from presynaptic terminals to maintain the Glu concentration in the extracellular space to prevent excitotoxicity (Danbolt, 2001). GS in the astrocytes converts Glu to Gln (Norenberg and Martinez-Hernandez, 1979; Hertz and Zielke, 2004), which is then released into the extracellular space (Lieth et al., 2001; Sibson et al., 2001). In the present study, the concentration of Gln increased at 1 week, without a significant increase in Glu concentration (Fig. 5). However, application of TFB-TBOA markedly increased Glu concentration (Fig. $7 B$ ), indicating that the level of Glu uptake through glial transporters increases after the stroke. Such an increase may have resulted in the enhancement of synthesis and release of Gln.

The mechanisms underlying the increased Glu uptake have not yet been fully clarified. As shown in Figure $6 B$, expression level of GLT-1 protein was not changed in the stroke mice despite the increase in mRNA expression level. On the other hand, TFBTBOA treatment markedly increased interstitial Glu levels. These results indicate that Glu uptake was activated not through an increase in GLT-1 protein but through activation of GLT-1. Uptake of Glu by Glu transporters is partly regulated by concentration of Glu in the astrocyte (Gorovits et al., 1997; Ottersen et al., 1996; Rossi et al., 2007). Thus, increase of Glu release from presynaptic terminals may passively increase the Glu uptake by astrocytes. Then increased intracellular Glu activates GS, reducing intracellular Glu concentration to maintain the concentration gradient. Furthermore, TFB-TBOA treatment disturbed the functional recovery of somatosensory function (Fig. 7C), indicating that the clearance of Glu by astrocytes during the period when synaptic turnover is activated to generate multiple inputs to each neuron plays an important role in functional reorganization after the stroke. Activation of synaptic turnover with the increase in synaptic inputs may induce an increase in Glu concentration in 
the extracellular space, which may induce excitotoxicity. This hypothesis is also consistent with the finding in present study (Fig. 7E). Such toxicity may be relieved by Glu uptake facilitated by activated astrocytes.

The activity of astrocytes increased particularly in response to ipsilateral limb stimulation after the stroke (Fig. 3A). Previous studies also showed an increase in intracellular calcium concentration in astrocytes in response to synaptic activation (Porter and McCarthy, 1996; Grosche et al., 1999; D’Ascenzo et al., 2007). Synaptically released Glu may act through mGluR5 (Parri et al., 2010) and/or other Glu receptor(s) in astrocytes to induce calcium transients. The increase in intracellular calcium concentration induces the release of gliotransmitters, such as Glu (Fellin et al., 2004), ATP (Guthrie et al., 1999), and D-serine (Panatier et al., 2006). The release of these transmitters controls neuronal excitability and synaptic transmission (Fellin et al., 2004; Serrano et al., 2006), which may contribute to the synaptic plasticity and remodeling of the neuronal circuit. In the present study, a significant increase in the amplitude of calcium transients, particularly in response to ipsilateral limb stimulation, was observed in astrocytes during the first week after the stroke (Fig. 3C). It is the period when the number of inputs from the ipsilateral limb to neurons increased (Fig. 2), and synaptic turnover rate markedly increased (Takatsuru et al., 2009).

Gln is a precursor of both Glu and GABA (Fonnum et al., 1997). Glu is taken up by astrocytes through Glu transporters and converted to Gln by GS. Because conversion of Glu to Gln by GS is an ATPdependent process, Glu that is taken up by astrocytes may not be converted efficiently under ischemic conditions (Gorovits et al., 1997), and thus Glu will accumulate in the astrocytic cytoplasm (Ottersen et al., 1996) in a peri-infarcted area. Such accumulated Glu is then released by depolarization of astrocytes (Rossi et al., 2007), inducing excitotoxicity. In this study, because all studies were done using intact hemisphere, oxygen and ATP supply should be enough to activate the astrocytic GS. As shown in Figure 7B, inhibition of GLT-1 by TFB-TBOA demonstrates that the releases of Glu from presynaptic terminals are increased in intact hemisphere of stroke-induced mice. Such increase of Glu induced the increase in uptake of Glu and synthesis of Gln in astrocytes. We also attempted to use a GS inhibitor (methionine sulfoximine) (Tsuboi et al., 2011 ) the same as the experiments of TFB-TBOA application to examine the effect of inhibition of increasing Gln. However, a lethal seizure was induced even at a small dose (200 nM; data not shown). As described above, inhibition of GS induces the accumulation of Glu in astrocytes. Accumulated Glu may have group (Bonferroni test).
B
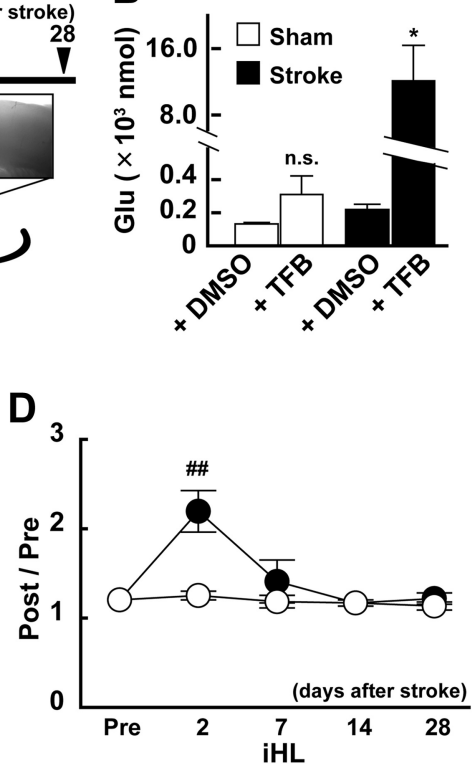

$\mathbf{F}$

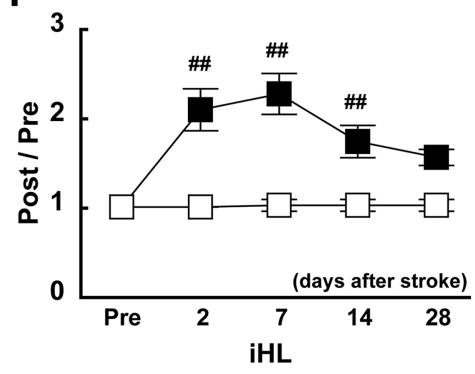

Figure 7. The function of glial Glu transporter was critical for functional recovery during the first week after the stroke. $\boldsymbol{A}$, Schematic drawing of TFB-TBOA injection experiment. TFB-TBOA (200 nM) was injected using the microdialysis technique 3 and $4 \mathrm{~d}$ the distance of diffused drug. $\boldsymbol{B}$, Concentration of Glu after TFB-TBOA or DMSO application. In vivo microdialysis was

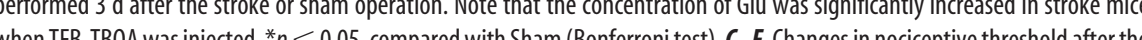
stroke and effect of TFB-TBOA treatment. The graphs show normalized data of von Frey test. A value $>1$ indicates that the threshold of sensation increases compared with that in Pre. The stroke induced a transient increase in the index induced by $\mathrm{iHL}$ stimulation only $2 \mathrm{~d}$ after the stroke $(\boldsymbol{D})$, whereas TFB-TBOA application significantly extended the duration until recovery $(\boldsymbol{F})$. TFB-TB0A application $(\boldsymbol{E}) .{ }^{\#} p<0.05$, compared with Pre in each group (Bonferroni test). ${ }^{\# \#} p<0.01$, compared with Pre in each

been released after the depolarization of astrocytes, inducing excitotoxicity.

By using TFB-TBOA, the concentration of Glu was extremely increased, even in 1 week mice (Fig. 7). When we increased the concentration of TFB-TBOA $>1 \mu \mathrm{M}$, a severe seizure was induced by critical increase of Glu concentration (data not shown). In contrast, application of low-dose (20 nM) TFB-TBOA also induced the delay of functional recovery (see Results). Thus, Glu transporter (i.e., GLT-1) should be involved in the decrease in concentration of interstitial Glu for protecting the excitotoxicity and support the remodeling of neuronal circuits. Overall, together with our previous study (Takatsuru et al., 2009), the present findings are consistent with our hypothesis that focal infarction activates astrocytes in the contralateral brain region, which is involved in functional compensation by controlling the synaptic organization through the prevention of excitotoxicity of extracellular Glu. 


\section{Astrocytes in intact hemisphere could be a potential therapeutic target in stroke patients}

The present study showed the involvement of contralateral astrocytes in functional recovery after a stroke, possible by removing excess amounts of Glu from the extracellular space. In the cerebral cortex, 90\% of Glu is taken by GLT-1 (Rothstein, 1996; Danbolt, 2001). Thus, if we can potentiate the function of GLT-1, it must be useful for accelerating recovery after a stroke. At present, however, there is no effective agonist that can activate GLT-1, except Glu. Rothstein et al. (2005) screened 1040 FDA-approved drugs and found that only $\beta$-lactam antibiotics (ceftriaxone) increase the activity of GLT-1 by increasing GLT-1 protein expression level. Other groups have also shown that harmine, a natural $\beta$-carboline alkaloid, induces the expression of GLT- 1 through the activation of PPAR $\gamma$-mediated transcription (Vermeiren et al., 2005; Romera et al., 2007; Li et al., 2011). However, these substances are not very potent agonists. For ceftriaxone, it takes at least several days to induce GLT-1 protein expression (Chu et al., 2007), and harmine is not the direct agonist of GLT-1. Recently, another group has shown that overexpression of the GLT-1 protein using a virus vector reduces ischemic brain injury (Harvey et al., 2011).

Although we have shown the possible involvement of GLT-1 on functional recovery, 50\% increase in GLT-1 mRNA expression resulted in only $20 \%$ increase in its protein level, which was not statistically significant (Fig. 6). Thus, the increase in GLT-1 in astrocyte may not contribute greatly to the decrease in interstitial Glu. Nevertheless, we showed that excitotoxicity of excess Glu secreted during synaptic organization may be relieved by activated astrocytes in the contralateral SSC, which may contribute greatly to functional recovery. In addition to the importance of GLT-1 in the ischemic region, we showed an important role of astrocytes in the intact hemisphere for functional recovery. Thus, these findings may be useful for constructing a novel therapeutic strategy for stroke patients.

In conclusion, we have shown the activation of cerebral astrocytes in the region contralateral to the site of cerebral infarction, which may contribute greatly to functional recovery possibly through the clearance of excess glutamate from the extracellular space. Our study has provided a novel clue that may provide an effective therapeutic approach for better rehabilitation of stroke patients.

\section{References}

Brito VI, Rozanski VE, Beyer C, Küppers E (2009) Dopamine regulates the expression of the glutamate transporter GLT-1 but not GLAST in developing striatal astrocytes. J Mol Neurosci 39:372-379. CrossRef Medline

Calautti C, Baron JC (2003) Functional neuroimaging studies of motor recovery after stroke in adults: a review. Stroke 34:1553-1566. CrossRef Medline

Cao Y, D’Olhaberriague L, Vikingstad EM, Levine SR, Welch KM (1998) Pilot study of functional MRI to assess cerebral activation of motor function after poststroke hemiparesis. Stroke 29:112-122. CrossRef Medline

Carmichael ST (2010) Targets for neural repair therapies after stroke. Stroke 41:S124-S126. CrossRef Medline

Chollet F, DiPiero V, Wise RJ, Brooks DJ, Dolan RJ, Frackowiak RS (1991) The functional anatomy of motor recovery after stroke in humans: a study with positron emission tomography. Ann Neurol 29:63-71. CrossRef Medline

Chu K, Lee ST, Sinn DI, Ko SY, Kim EH, Kim JM, Kim SJ, Park DK, Jung KH, Song EC, Lee SK, Kim M, Roh JK (2007) Pharmacological induction of ischemic tolerance by glutamate transporter-1 (EAAT2) upregulation. Stroke 38:177-182. CrossRef Medline

Crosson B, McGregor K, Gopinath KS, Conway TW, Benjamin M, Chang YL, Moore AB, Raymer AM, Briggs RW, Sherod MG, Wierenga CE, White KD (2007) Functional MRI of language in aphasia: a review of the literature and the methodological challenges. Neuropsychol Rev 17:157-177. CrossRef Medline

Danbolt NC (2001) Glutamate uptake. Prog Neurobiol 65:1-105. CrossRef Medline

D’Ascenzo M, Fellin T, Terunuma M, Revilla-Sanchez R, Meaney DF, Auberson YP, Moss SJ, Haydon PG (2007) mGluR5 stimulates gliotransmission in the nucleus accumbens. Proc Natl Acad Sci U S A 104:1995-2000. CrossRef Medline

Ellison JA, Barone FC, Feuerstein GZ (1999) Matrix remodeling after stroke: de novo expression of matrix proteins and integrin receptors. Ann N Y Acad Sci 890:204-222. CrossRef Medline

Eto K, Wake H, Watanabe M, Ishibashi H, Noda M, Yanagawa Y, Nabekura J (2011) Inter-regional contribution of enhanced activity of the primary somatosensory cortex to the anterior cingulate cortex accelerates chronic pain behavior. J Neurosci 31:7631-7636. CrossRef Medline

Fellin T, Pascual O, Gobbo S, Pozzan T, Haydon PG, Carmignoto G (2004) Neuronal synchrony mediated by astrocytic glutamate through activation of extrasynaptic NMDA receptors. Neuron 43:729-743. CrossRef Medline

Fonnum F, Johnsen A, Hassel B (1997) Use of fluorocitrate and fluoroacetate in the study of brain metabolism. Glia 21:106-113. CrossRef Medline

Gorovits R, Avidan N, Avisar N, Shaked I, Vardimon L (1997) Glutamine synthetase protects against neuronal degeneration in injured retinal tissue. Proc Natl Acad Sci U S A 94:7024-7029. CrossRef Medline

Grosche J, Matyash V, Möller T, Verkhratsky A, Reichenbach A, Kettenmann H (1999) Microdomains for neuron-glia interaction: parallel fiber signaling to Bergmann glial cells. Nat Neurosci 2:139-143. CrossRef Medline

Guthrie PB, Knappenberger J, Segal M, Bennett MV, Charles AC, Kater SB (1999) ATP released from astrocytes mediates glial calcium waves. J Neurosci 19:520-528. Medline

Harvey BK, Airavaara M, Hinzman J, Wires EM, Chiocco MJ, Howard DB, Shen H, Gerhardt G, Hoffer BJ, Wang Y (2011) Targeted overexpression of glutamate transporter 1 (GLT-1) reduces ischemic brain injury in a rat model of stroke. PLoS One 6:e22135. CrossRef Medline

Hertz L, Zielke HR (2004) Astrocytic control of glutamatergic activity: astrocytes as stars of the show. Trends Neurosci 27:735-743. CrossRef Medline

Kaneko R, Kawaguchi M, Toyama T, Taguchi Y, Yagi T (2009) Expression levels of protocadoherin- $\alpha$ transcripts are decreased by nonsensemediated mRNA decay with frameshift mutations and by high DNA methylation in their promoter regions. Gene 430:86-94. CrossRef Medline

Kerr JN, Greenberg D, Helmchen F (2005) Imaging input and output of neocortical networks in vivo. Proc Natl Acad Sci U S A 102:14063-14068. CrossRef Medline

Li Y, Sattler R, Yang EJ, Nunes A, Ayukawa Y, Akhtar S, Ji G, Zhang PW, Rothstein JD (2011) Harmine, a natural $\beta$-carboline alkaloid, upregulates astroglial glutamate transporter expression. Neuropharmacology 60; 1168-1175. CrossRef Medline

Lieth E, LaNoue KF, Berkich DA, Xu B, Ratz M, Taylor C, Hutson SM (2001) Nitrogen shuttling between neurons and glial cells during glutamate synthesis. J Neurochem 76:1712-1723. CrossRef Medline

Norenberg MD, Martinez-Hernandez A (1979) Fine structural localization of glutamine synthetase in astrocytes of rat brain. Brain Res 161:303-310. CrossRef Medline

Olson EE, McKeon RJ (2004) Characterization of cellular and neurological damage following unilateral hypoxia/ischemia. J Neurol Sci 227:7-19. CrossRef Medline

Ottersen OP, Laake JH, Reichelt W, Haug FM, Torp R (1996) Ischemic disruption of glutamate homeostasis in brain: quantitative immunocytochemical analyses. J Chem Neuroanat 12:1-14. CrossRef Medline

Panatier A, Theodosis DT, Mothet JP, Touquet B, Pollegioni L, Poulain DA, Oliet SH (2006) Glia-derived D-serine controls NMDA receptor activity and synaptic memory. Cell 125:775-784. CrossRef Medline

Parent M, Bush D, Rauw G, Master S, Vaccarino F, Baker G (2001) Analysis of amino acids and catecholamines, 5-hydroxytryptamine and their metabolites in brain areas in the rat using in vivo microdialysis. Methods 23:11-20. CrossRef Medline

Parri HR, Gould TM, Crunelli V (2010) Sensory and cortical activation of 
distinct glial cell subtypes in the somatosensory thalamus of young rats. Eur J Neurosci 32;29-40. CrossRef Medline

Pfrieger FW (2010) Role of glial cells in the formation and maintenance of synapses. Brain Res Rev 63:39-46. CrossRef Medline

Porter JT, McCarthy KD (1996) Hippocampal astrocytes in situ respond to glutamate released from synaptic terminals. J Neurosci 16:5073-5081. Medline

Reinecke S, Dinse HR, Reinke H, Witte OW (2003) Induction of bilateral plasticity in sensory cortical maps by small unilateral cortical infarcts in rats. Eur J Neurosci 17:623-627. CrossRef Medline

Romera C, Hurtado O, Mallolas J, Pereira MP, Morales JR, Romera A, Serena J, Vivancos J, Nombela F, Lorenzo P, Lizasoain I, Moro MA (2007) Ischemic preconditioning reveals that GLT-1/EAAT2 glutamate transporter is a novel PPARc target gene involved in neuroprotection. J Cereb Blood Flow Metab 27:1327-1338. CrossRef Medline

Rossi DJ, Brady JD, Mohr C (2007) Astrocyte metabolism and signaling during brain ischemia. Nat Neurosci 10:1377-1386. CrossRef Medline

Rothstein JD (1995) Excitotoxicity and neurodegeneration in amyotrophic lateral sclerosis. Clin Neurosci 3:348-359. Medline

Rothstein JD, Patel S, Regan MR, Haenggeli C, Huang YH, Bergles DE, Jin L, Dykes Hoberg M, Vidensky S, Chung DS, Toan SV, Bruijn LI, Su ZZ, Gupta P, Fisher PB (2005) $\beta$-Lactam antibiotics offer neuroprotection by increasing glutamate transporter expression. Nature 433:73-77. CrossRef Medline

Serrano A, Haddjeri N, Lacaille JC, Robitaille R (2006) GABAergic network activation of glial cells underlies hippocampal heterosynaptic depression. J Neurosci 26:5370-5382. CrossRef Medline

Shimamoto K, Sakai R, Takaoka K, Yumoto N, Nakajima T, Amara SG, Shigeri Y (2004) Characterization of novel L-threo-beta-benzyloxyaspartate derivatives, potent blockers of the glutamate transporters. Mol Pharmacol 65:10081015. CrossRef Medline

Shimokawa N, Haglund K, Hölter SM, Grabbe C, Kirkin V, Koibuchi N, Schultz C, Rozman J, Hoeller D, Qiu CH, Londoño MB, Ikezawa J, Jedlicka P, Stein B, Schwarzacher SW, Wolfer DP, Ehrhardt N, Heuchel R, Nezis I, Brech A, et al. (2010) CIN85 regulates dopamine receptor endocytosis and governs behaviour in mice. EMBO J 29:2421-2432. CrossRef Medline

Sibson NR, Mason GF, Shen J, Cline GW, Herskovits AZ, Wall JE, Behar KL, Rothman DL, Shulman RG (2001) In vivo (13)C NMR measurement of neurotransmitter glutamate cycling, anaplerosis and TCA cycle flux in rat brain during (2-13C)glucose infusion. J Neurochem 76:975-989. CrossRef Medline

Takatsuru Y, Fukumoto D, Yoshitomo M, Nemoto T, Tsukada H, Nabekura J (2009) Neuronal circuit remodeling in the contralateral cortical hemisphere during functional recovery from cerebral infarction. J Neurosci 29:10081-10086. CrossRef Medline

Takayasu Y, Iino M, Takatsuru Y, Tanaka K, Ozawa S (2009) Functions of glutamate transporters in cerebellar Purkinje cell synapses. Acta Physiol (Oxf) 197:1-12. CrossRef Medline

Theodosis DT, Poulain DA, Oliet SH (2008) Activity-dependent structural and functional plasticity of astrocyte-neuron interactions. Physiol Rev 88:983-1008. CrossRef Medline

Tsuboi Y, Iwata K, Dostrovsky JO, Chiang CY, Sessle BJ, Hu JW (2011) Modulation of astroglial glutamine synthetase activity affects nociceptive behaviour and central sensitization of medullary dorsal horn nociceptive neurons in a rat model of chronic pulpitis. Eur J Neurosci 34:292-302. CrossRef Medline

Tsukada S, Iino M, Takayasu Y, Shimamoto K, Ozawa S (2005) Effects of a novel glutamate transporter blocker, (2S, 3S)-3-[3-[4-(trifluoromethyl) benzoylamino] benzyloxy] aspartate (TFB-TBOA), on activities of hippocampal neurons. Neuropharmacology 48:479-491. CrossRef Medline

Vermeiren C, Najimi M, Vanhoutte N, Tilleux S, de Hemptinne I, Maloteaux JM, Hermans E (2005) Acute up-regulation of glutamate uptake mediated by mGluR5a in reactive astrocytes. J Neurochem 94:405-416. CrossRef Medline

Ward NS (2007) Future perspectives in functional neuroimaging in stroke recovery. Eur Medicophys 43:285-294. Medline

Winship IR, Murphy TH (2008) In vivo calcium imaging reveals functional rewiring. J Neurosci 28:6592-6606. CrossRef Medline

Winship IR, Plaa N, Murphy TH (2007) Rapid astrocyte calcium signals correlate with neuronal activity and onset of the hemodynamic response in vivo. J Neurosci 27:6268-6272. CrossRef Medline

Zhang ZG, Bower L, Zhang RL, Chen S, Windham JP, Chopp M (1999) Three-dimensional measurement of cerebral microvascular plasma perfusion, glial fibrillary acidic protein and microtubule associated protein-2 immunoreactivity after embolic stroke in rats: a double fluorescent labeled laser-scanning confocal microscopic study. Brain Res 844:55-66. CrossRef Medline

Zhao Y, Rempe DA (2010) Targeting astrocytes for stroke therapy. Neurotherapeutics 7:439-451. CrossRef Medline 